\title{
Reply to "Phase II prospective randomized trial of weight loss prior to radical prostatectomy"
}

\author{
W. Demark-Wahnefried $\mathbb{1}^{1,2} \cdot$ S. Rais-Bahrami $\mathbb{1}^{2,3,4} \cdot$ R. A. Desmond ${ }^{2,5} \cdot$ J. B. Gordetsky ${ }^{2,3,6} \cdot$ M. Azrad ${ }^{1}$ A. D. Frugé ${ }^{1}$ \\ E. S. Yang ${ }^{2,7} \cdot$ L. A. Norian ${ }^{1,2} \cdot$ W. E. Grizzle ${ }^{2,6}$
}

Received: 22 December 2017 / Accepted: 28 December 2017 / Published online: 24 April 2018

(c) The Author(s) 2018. This article is published with open access

We commend Henning et al. [1] and their randomized controlled trial of a weight loss intervention (WLI) among prostate cancer patients in the presurgical setting. Abbreviated study periods and complicated logistics make these trials challenging. We speak from experience, since we completed a trial of similar design [2-4]. While Henning et al. discussed our trial [1-3], our findings were not presented, possibly due to publication overlap [4]. Both trials were undertaken with the same scientific premise: weight loss would slow tumor proliferation and reduce biomarkers of insulin signaling, inflammation, and androgenic control. Thus, we submit this letter to compare and contrast these two pioneering efforts.

Both trials employed open label, 2-arm randomized controlled designs in which participants were assigned to a WLI or wait-list control. Henning et al. [1] prescribed a structured diet plan of 1200 or $1500 \mathrm{kcal} /$ day that utilized meal replacements and $1 \mathrm{~h} /$ day of aerobic, resistance training, and stretching exercises. In our trial [2, 4], men were counseled to achieve dietary deficits of $1000 \mathrm{kcal} / \mathrm{day}$ and $250 \mathrm{kcal} /$ day of aerobic exercise.

$\triangle$ W. Demark-Wahnefried

demark@uab.edu

1 Department of Nutrition Sciences, University of Alabama at Birmingham (UAB), Birmingham, AL, USA

2 UAB Comprehensive Cancer Center, Birmingham, AL, USA

3 Department of Urology, UAB, Birmingham, AL, USA

4 Department of Radiology, UAB, Birmingham, AL, USA

5 Department of Preventive Medicine, UAB, Birmingham, AL, USA

6 Department of Pathology, Division of Anatomic Pathology, UAB, Birmingham, AL, USA

7 Department of Radiation Oncology, UAB, Birmingham, AL, USA
Henning et al. [1] stopped accrual early; 44 participants were enrolled and 34 (18 controls/16 WLI) completed. Our accrual target of 40 was achieved, and we had 34 trial completers ( 16 controls/18 WLI) [4]. Samples were similar, with men of mean age 60-63, body mass indexes of 30-33, and $\sim 30 \%$ African-Americans. Inclusion/exclusion criteria were comparable, though Henning et al. [1] excluded men with diabetes (diabetics comprised $25 \%$ of our sample) [2]; mean days on intervention was 51 vs. 47 days, respectively.

While our study period was shorter [4], our WLI group lost 4.7 vs. $3.7 \mathrm{~kg}$ [1]. Both trials experienced "drop-in"; our controls lost $2.2 \mathrm{~kg}$ and the Henning et al. controls lost 1.6 $\mathrm{kg}[1,4]$. Both trials found significant, yet dissimilar, between-arm differences in biomarkers. Henning et al. [1] reported significantly reduced triglycerides, LDL-cholesterol, and insulin with the WLI (but, no differences in leptin, total testosterone, sex hormone binding globulin [SHBG], and cytokines), whereas we found significant reductions in leptin and increases in total testosterone and SHBG, and also no differences in cytokines or insulin [4]. Neither trial reported between-arm differences in prostate-specific antigen $[1,4]$.

Importantly, neither trial observed lower proliferation rates with the WLI that were hypothesized [1]. Figure 3 of Henning et al. [1] shows Ki67 as $\sim 7 \%$ in the WLI vs. $\sim 6 \%$ among controls, though no significant differences were found using independent $t$-tests. We found significantly higher Ki67 in the WLI vs. controls using similar statistical tests (unpublished), and non-parametric tests on pre-/postpaired data (since we also had biopsy data). Therefore, unlike Henning et al. we hesitate to support the statement, "future more intensive weight loss interventions trials are warranted", since this preliminary evidence suggests that rapid weight loss may incite greater, rather than reduced proliferation, and our tumor gene expression data suggest upregulation of several genes associated with increased transcription, proliferation, and migration. More investigation is needed, but instead we advocate for studies that will 
provide a better understanding of the optimal rate of weight loss, and the role of physical activity in influencing tumor biology.

\section{Compliance with ethical standards}

Conflict of interest While none of the following relationships affect the content of this letter, in the spirit of full disclosure, we acknowledge the following: SR-B (Philips/InVivo Corp.: Advisor); ESY (Bayer, Inc.: Advisor/Nanostring Technologies: Honoraria/Lilly, Inc. and Abbvie, Inc. Research Funding); WEG (TEVA and Amgen; Stock Ownership/Bristol-Myers Squibb: Advisor, Honoraria and Travel).

Open Access This article is licensed under a Creative Commons Attribution-NonCommercial-NoDerivatives 4.0 International License, which permits any non-commercial use, sharing, distribution and reproduction in any medium or format, as long as you give appropriate credit to the original author(s) and the source, and provide a link to the Creative Commons license. You do not have permission under this license to share adapted material derived from this article or parts of it. The images or other third party material in this article are included in the article's Creative Commons license, unless indicated otherwise in a credit line to the material. If material is not included in the article's Creative Commons license and your intended use is not permitted by statutory regulation or exceeds the permitted use, you will need to obtain permission directly from the copyright holder. To view a copy of this license, visit http://creativecommons.org/licenses/by-nc-nd/4.0/.

\section{References}

1. Henning SM, Galet C, Gollapudi K, Byrd JB, Liang P, Li Z, et al. Phase II prospective randomized trial of weight loss prior to radical prostatectomy. Prostate Cancer Prostatic Dis. 2017. https://doi.org/ 10.1038/s41391-017-0001-1.

2. Demark-Wahnefried W, Nix JW, Hunter GR, Rais-Bahrami S, Desmond RA, Chacko B, et al. Feasibility outcomes of a presurgical randomized controlled trial exploring the impact of caloric restriction and increased physical activity versus a wait-list control on tumor characteristics and circulating biomarkers in men electing prostatectomy for prostate cancer. BMC Cancer. 2016;16:61.

3. Fruge AD, Ptacek T, Tsuruta Y, Morrow CD, Azrad M, Desmond RA, et al. Dietary changes impact the gut microbe composition in overweight and obese men with prostate cancer undergoing radical prostatectomy. J Acad Nutr Diet. 2016. https://doi.org/10.1016/j.ja nd.2016.10.017.

4. Demark-Wahnefried W, Rais-Bahrami S, Desmond RA, Gordetsky J, Hunter G, Yang E, et al. Presurgical weight loss affects tumour traits and circulating biomarkers in men with prostate cancer. Br J Cancer. 2017;117:1303-13. 